\title{
Erythroxylaceae no Rio Grande do Norte, Brasil
}

\author{
Erythroxylaceae of Rio Grande do Norte, Brazil
}

James Lucas da Costa-Lima ${ }^{1,4}$, Maria Iracema Bezerra Loiola ${ }^{2}$ \& Jomar Gomes Jardim ${ }^{3}$

\begin{abstract}
Resumo
O presente estudo tem como objetivo contribuir para o conhecimento das espécies de Erythroxylaceae ocorrentes no estado do Rio Grande do Norte. O trabalho tem por base a análise morfológica de materiais depositados em herbários e coletas de campo, além da compilação de dados de literatura. Foram registradas 11 espécies: Erythroxylum barbatum, E. caatingae, E. nummularia, E. passerinum, E. pungens, E. revolutum, E. rimosum, E. simonis, E. squamatum, E. subrotundum e E. vacciniifolium, das quais sete são citadas pela primeira vez no Rio Grande do Norte. Chave para identificação, descrições, ilustrações, dados sobre hábitat, fenologia e distribuição geográfica das espécies são apresentados.
\end{abstract}

Palavras-chave: Erythroxylum, florística, Nordeste do Brasil, taxonomia.

\begin{abstract}
This study focuses on the Erythroxylaceae found in the state of Rio Grande do Norte, Northeast Brazil. It is based on a morphological analysis of herbaria collections, as well as on a review of the relevant literature and on collections in the field. A total of 11 species were recorded for the state: Erythroxylum barbatum, E. caatingae, E. nummularia, E. passerinum, E. pungens, E. revolutum, E. rimosum, E. simonis, E. squamatum, E. subrotundum and E. vacciniifolium, of which seven are new records for Rio Grande do Norte. An identification key, descriptions, illustrations, habitat data, phenology, and species distribution are also provided.
\end{abstract}

Key words: Erythroxylum, floristic inventories, Northeastern Brazil, taxonomy.

\section{Introdução}

Erythroxylaceae Kunth compreende cerca de 240 espécies distribuídas em quatro gêneros: Aneulophus Benth., Erythroxylum P. Browne, Nectaropetalum Engl. e Pinacopodium Exell \& Mendonça. Apenas Erythroxylum é amplamente distribuído e os demais são restritos à África Tropical. Tal gênero apresenta aproximadamente 230 espécies com maior representatividade na Região Neotropical (com 187 táxons) e tem como principais centros de diversidade e endemismo o Brasil e a Venezuela (Plowman \& Berry 1999; Daly 2004). No Brasil são registradas 118 espécies com maior diversidade no Domínio da Mata Atlântica, especialmente na Região Nordeste onde são registradas 40 espécies (Loiola \& Costa-Lima 2014).

Os tratamentos taxonômicos mais importantes para a família, em especial para as espécies de
Erythroxylum do Brasil, foram Martius (1843), Peyritsch (1878), e Schulz (1907). No Brasil a diversidade de espécies do gênero pode ser evidenciada nas Floras de alguns estados e localidades (e.g., Huber 1909; Kuhlmann \& Rodrigues 1957; Amaral Jr. 1980; Sobral 1987; Zappi 1995; Amaral Jr. 1996; Dubs 1998; Mendonça et al. 1998; Mendonça \& Amaral Jr. 2002a; 2002b; Barbosa \& Amaral 2001; Patrício \& Pirani 2002; Loiola 2004; Prance 2006; Loiola et al. 2007; Loiola \& Gomes 2009; Costa-Lima et al. 2013). É considerável o número de trabalhos que propõem a descrição de novas espécies de Erythroxylum para o território brasileiro, especialmente para a Amazônia (Amaral Jr. 1976; Plowman 1984) e para a Região Nordeste (Plowman 1983; 1986; 1987; Amaral Jr. 1990; Loiola \& Sales 2008; 2012; Costa-Lima \& Alves 2013; Costa-Lima et al. 2014).

\footnotetext{
${ }^{1}$ Universidade Federal do Vale do São Francisco, Programa de Conservação da Fauna e da Flora, Av. José de Sá Maniçoba s/n, 56304-205, Petrolina, PE, Brasil.

${ }^{2}$ Universidade Federal do Ceará, Depto. Biologia, Campus do Pici, bl. 906, 60455-970, Fortaleza, CE, Brasil.

${ }^{3}$ Universidade Federal do Rio Grande do Norte, Depto. Botânica, Ecologia e Zoologia, Campus Universitário, Lagoa Nova, 59078-970, Natal, RN, Brasil.

${ }^{4}$ Autor para correspondência: jimcostalima@yahoo.com.br
} 
Até o presente momento, as espécies de Erythroxylaceae do Rio Grande do Norte eram apenas citadas em listas florísticas, quase sempre erroneamente determinadas. Loiola \& CostaLima (2014) relatam a ocorrência de quatro espécies para o referido estado: Erythroxylum caatingae Plowman, E. revolutum Mart., E. rimosum O.E.Schulz e E. subrotundum A.St.Hil. No entanto, tal diversidade parece bastante subestimada. Assim, como parte do projeto "Flora do Rio Grande do Norte", o presente estudo teve por objetivo inventariar as Erythroxylaceae desse Estado, elaborando descrições, chave de identificação, ilustrações e comentários sobre distribuição geográfica das espécies.

\section{Material e Métodos}

As coletas ocorreram esporadicamente entre os anos de 2010 e 2012 em diferentes municípios e tipos de vegetação do território norte-riograndense. Após processamento, o material foi incorporado ao acervo do herbário UFRN, seguindo-se metodologia proposta por Mori et al. (1989). Além do material coletado, foram examinados materiais já depositados no herbário UFRN, assim como espécimes dos seguintes herbários, incluindo imagens e tipos: ALCB, CTES, EAC, EAN, HRB, HST*', HUEFS, HUVA*, IPA, JPB, MBM, MOSS, PEUFR, R, RB, TEPB e UFP, (acrônimos segundo Thiers, continuamente atualizado) $\left[{ }^{*}=\right.$ não indexado]. A identificação dos táxons foi realizada por meio de análise comparativa com descrições originais encontradas em bibliografias especializadas (e.g., Martius 1843; Peyritsch 1878; Schulz 1907; Plowman 1983; 1984; $1986 ; 1987$; 1988) e por comparação com materiais previamente identificados por especialistas. Para a abreviação dos nomes dos autores dos táxons adotou-se Brummit \& Powell (1992). A descrição morfológica do material baseou-se em Radford et al. (1974) e Stearn (1992). As ilustrações foram elaboradas a partir de material fixado em álcool a $70 \%$, bem como de amostras herborizadas. Dados fenológicos e ambientes preferenciais foram obtidos a partir dos rótulos das exsicatas ou durante as coletas.

\section{Resultados e Discussão}

Foram registradas 11 espécies distribuídas em três seções, de acordo com a classificação infragenérica proposta por Schulz (1907). São elas Erythroxylum sect. Archerythroxylum O.E.Schulz:
Erythroxylum caatingae, E. nummularia Peyr., E. subrotundum e E. vacciniifolium Mart.; E. sect. Pogonophorum O.E.Schulz: E. barbatum O.E.Schulz; e E. sect. Rhabdophyllum O.E.Schulz: E. passerinum Mart., E. pungens O.E.Schulz, E. revolutum, E. rimosum, E. simonis Plowman e $E$. squamatum $\mathrm{Sw}$. Dentre as espécies encontradas, sete tem aqui sua ocorrência citada pela primeira vez no estado do Rio Grande do Norte, a saber: Erythroxylum barbatum, E. passerinum, E. pungens, E. revolutum, E. simonis, E. squamatum e E. vacciniifolium. As espécies de Erythroxylum foram encontradas em diferentes tipos de vegetação: cinco delas tem ocorrência exclusiva em tipos de vegetação do Domínio da Mata Atlântica e três outras aos da Caatinga, já E. revolutum, E. subrotundum e $E$. vacciniifolium ocorrem em mais de um tipo de vegetação desses dois Domínios.

\section{Tratamento taxonômico}

Erythroxylaceae Kunth, Nov. Gen. Sp. 5: 175. 1821.

Erythroxylum P. Browne, Civ. Nat. Hist. Jamaica 1: 278.1756.

Arbustos ou árvores, córtex em geral estriado, raro suberoso, escasso a densamente lenticelado. Estípulas intrapeciolares, lisas ou estriadas longitudinalmente, 2-3-setulosas no ápice ou não, coléteres presentes; catafilos persistentes, dísticos ou imbricados, geralmente semelhantes às estípulas, frequentemente adensados formando ramos encurtados (braquiblastos). Folhas alternas, glabras, simples; pecíolo subcilíndrico, canaliculado na face superior. Inflorescências fasciculadas ou unifloras, na axila das folhas e/ ou catafilos; bractéolas 2 a numerosas. Flores 5-meras, andróginas, heterostílicas; pétalas com apêndice ligulado internamente com 1-2 pares de aurículas; estames 10, isodínamos ou em duas séries de 5 , filetes unidos na base; ovário súpero, 3-carpelar, 3-locular, geralmente com apenas 1 óvulo desenvolvido; estiletes 3 , livres ou concrescidos. Drupa carnosa; pirênio 1, em geral elíptico, cilíndrico, trígono ou multi-sulcado longitudinalmente em secção transversal.

No Brasil são registradas 118 espécies de Erythroxylum, das quais 79 tem distribuição restrita ao país. Ocorrem desde florestas úmidas, como na Floresta Atlântica e Amazônia, até formações abertas e mais secas, como as diferentes fisionomias das Caatingas e Cerrados (Loiola \& Costa-Lima 2014). 


\section{Chave para identificação das espécies de Erythroxylum do Rio Grande do Norte}

1. Estípulas lisas.

2. Estípulas 3-setulosas no ápice; lâmina foliar elíptica a largo-elíptica

11. Erythroxylum vacciniifolium

2'. Estípulas 2-setulosas no ápice; lâmina foliar obovada, oblonga ou suborbicular.

3. Estípulas com coléteres inconspícuos; folhas concentradas no ápice dos ramos encurtados (braquiblastos); pedicelo 0,6-2 mm compr., flores brevistilas com estiletes concrescidos na base; pirênio trígono em secção transversal 2. Erythroxylum caatingae

3'. Estípulas com coléteres conspícuos e vilosos; folhas distribuídas ao longo dos ramos; pedicelo 2-4,5 mm compr., flores brevistilas com estiletes livres entre si; pirênio 6-sulcado longitudinalmente em secção transversal.

4. Lâmina foliar cartácea, ápice emarginado a obcordado, venação secundária com 8-10 pares 3. Erythroxylum nummularia

4'. Lâmina foliar membranácea, ápice obtuso a apiculado, venação secundária com 5-7 pares 10. Erythroxylum subrotundum

1'. Estípulas estriadas longitudinalmente.

5. Estípulas pelo menos o dobro do comprimento do pecíolo, coléteres conspícuos e densamente vilosos; lobos do cálice 4-6 mm compr. 1. Erythroxylum barbatum

5'. Estípulas do mesmo tamanho a menores que o pecíolo, coléteres inconspícuos ou fimbriolados; lobos do cálice $0,6-2,3 \mathrm{~mm}$ compr.

6. Ramos com ritidoma papiráceo; cálice com prefloração contorcida, lobos oblongos, ápice cuspidado 7. Erythroxylum rimosum

6'. Ramos com ritidoma liso; cálice com prefloração valvar, lobos triangulares, ápice agudo a acuminado.

7. Lâmina foliar com margem frequentemente revoluta, raro plana; pedicelo $0,5-2 \mathrm{~mm}$ compr.

7'. Lâmina foliar com margem plana; pedicelo 2,5-15 mm compr.

8. Lâmina foliar oblonga a obovada, raro suborbicular, ápice obtuso a retuso; pedicelo (3)6-15 mm compr., pétala plana 5. Erythroxylum pungens

8'. Lâmina foliar elíptica, estreito-elíptica ou largo-elíptica, ápice agudo, acuminado ou cuspidado; pedicelo 2,5-6,6 mm compr., pétala côncava.

9. Lâmina foliar membranácea; tubo estaminal maior que os lobos do cálice; pirênio cilíndrico em secção transversal ............... 8. Erythroxylum simonis

9'. Lâmina foliar cartácea; tubo estaminal menor que os lobos do cálice; pirênio 6-sulcado longitudinalmente em secção transversal.

10. Lâmina foliar com ápice agudo; fascículos distribuídos ao longo dos ramos 4. Erythroxylum passerinum

10'. Lâmina foliar com ápice cuspidado; fascículos concentrados nos ramos encurtados (braquiblastos) 9. Erythroxylum squamatum

\section{Erythroxylum barbatum O.E.Schulz in Engl.,} Pflanzenr. 4(134): 21. 1907.

Arvoretas, 2-4 m alt.; ramos com ritidoma liso, lenticelas presentes. Estípulas 3-6 mm compr., estriadas longitudinalmente, estreito-triangulares, 3-setulosas, coléteres densamente vilosos; catafilos laxamente distribuídos nos ramos. Lâmina foliar membranácea a cartácea, obovada a oblonga, 6,2-10 $\times 3-5,2 \mathrm{~cm}$, base cuneada, margem plana, ápice obtuso; venação secundária 10-12 pares, dispostos alternadamente; pecíolo 1-2 mm compr. Fascículos
1-3 flores; pedicelo 3,2-5 mm compr.; cálice com prefloração valvar, lobos 4-6 × 1-1,4 mm, estreitotriangulares, ápice agudo; pétala 3,5-4,5 mm compr., oblonga, margem inteira, côncava; tubo estaminal $0,8-1,2 \mathrm{~mm}$ compr.; flores brevistilas: filetes $3,5-4,2$ mm compr., anteras $0,4-0,5 \times 0,3-0,5 \mathrm{~mm}$, estiletes 1-1,5 mm compr., livres; flores longistilas não observadas; ovário 1-1,5 × 1-1,2 mm, obovoide a elipsoide. Drupa 8-10 × 4,6-5,8 mm, elipsoide, enegrecida quando madura; pirênio 6-sulcado longitudinalmente em secção transversal. 
Material examinado: Portalegre, rod. para Serrinha dos Pintos, 30.IV.2012, fr., J.G. Jardim et al. 6233 (UFP, UFRN).

Material examinado adicional: BRASIL. CEARÁ: Graça, 19.XII.2007, fl., V.V. Falconi et al. 10 (HUVA, UFRN). PIAUÍ: Uruçuí, Uruçuí Preto, 19.XI.2005, fl., A.M. Miranda et al. 5233 (HST, UFRN).

Ocorre na porção centro-norte do Brasil, no Centro-Oeste (Goiás, Mato Grosso), Nordeste (Ceará, Bahia, Maranhão, Piauí) e Norte (Pará), em diversas formações vegetais, especialmente nas de Caatinga e Cerrado (Loiola \& Costa-Lima 2014). Está sendo aqui referida pela primeira vez no Rio Grande do Norte, onde foi coletada em floresta estacional semidecídua interiorana com frutos no mês de abril.

Diferencia-se das demais espécies que ocorrem no estado pelas estípulas com coléteres densamente vilosos e pelos lobos do cálice estreitotriangulares com 4-6 mm compr.

2. Erythroxylum caatingae Plowman, Fieldiana, Bot. 19: 5, fig. 3. 1987.

Fig. 1a-d

Arbustos a arvoretas, 2-3 m alt.; ramos com ritidoma liso, lenticelas presentes. Estípulas 2,5-5,3 mm compr., lisas, triangulares, 2-setulosas, coléteres inconspícuos; catafilos adensados formando braquiblastos. Lâmina foliar, cartácea a subcoriácea, obovada a oblonga, 2-5,8 $\times 0,8-2,4$ $\mathrm{cm}$, base cuneada, margem plana, ápice obtuso a retuso; venação secundária 12-16 pares, dispostos alternadamente; pecíolo 5,3-10,5 mm compr. Fascículos 1-3 flores; pedicelo 0,6-2 mm compr.; cálice com prefloração valvar, lobos 1,2-1,8 × 1-1,5 mm, triangulares, ápice agudo; pétala 2-3 mm compr., ovada, margem inteira, côncava; tubo estaminal 1-1,6 $\mathrm{mm}$ compr.; flores brevistilas: filetes 1,5-2,5 mm compr., anteras $0,5-0,6 \times$ ca. $0,5 \mathrm{~mm}$, estiletes $0,8-1,2 \mathrm{~mm}$ compr., concrescidos na base; flores longistilas não observadas; ovário $1-1,5 \times 1-1,2 \mathrm{~mm}$, obovoide. Drupa 6,5-8,2 $\times$ 4,2-6 mm, elipsoide, vermelha quando madura; pirênio trígono em secção transversal.

Material examinado: Coronel João Pessoa, Serra São José, 7.V.1984, fl. e fr., A.C. Sarmento \& J. Assis 747 (CTES foto, HRB, MBM foto, RB). Serra São João, 19.VII.1991, st., M.A. Figueiredo et al. 339 (EAC, MOSS, TEPB).

Ocorre em áreas de caatinga nos estados da Bahia, Ceará, Paraíba, Pernambuco e Rio Grande do Norte (Loiola \& Costa-Lima 2014). Neste último, encontrada com flores e frutos em maio.
É distinta das demais espécies pelas estípulas lisas associadas às flores subsésseis e drupa com pirênio trígono em secção transversal.

3. Erythroxylum nummularia Peyr. in Mart., Fl. bras. 12(1): 133, t. 23, f. 3. $1878 . \quad$ Fig. 1e-h

Arbustos, 1,5-2 m alt.; ramos com ritidoma liso, lenticelas presentes. Estípulas 1-2 mm compr., lisas, triangulares, 2-setulosas, coléteres vilosos; catafilos laxamente distribuídos nos ramos, às vezes adensados formando braquiblastos. Lâmina foliar cartácea, obovada, 1-3 × 1,2-2,2 cm, base aguda, margem plana, ápice emarginado a obcordado; venação secundária $8-10$ pares, dispostos alternadamente; pecíolo $0,5-1,8 \mathrm{~mm}$ compr. Fascículos 1-3 flores; pedicelo 2-3 mm compr.; cálice com prefloração valvar, lobos $0,8-$ 1,5 × 1-1,4 mm, largo-triangulares, ápice agudo; pétala 2,5-3,6 mm compr., elíptica, margem inteira, côncava; tubo estaminal 0,6-1 mm compr.; flores brevistilas: filetes $2,6-3,4 \mathrm{~mm}$ compr., anteras $0,3-0,5 \times$ ca. $0,3 \mathrm{~mm}$, estiletes $0,8-1,2 \mathrm{~mm}$ compr., livres; flores longistilas não observadas; ovário $0,8-1 \times 0,6-0,8 \mathrm{~mm}$, ovoide a elipsoide. Drupa $8-9,5 \times 3,4-4,5 \mathrm{~mm}$, ovoide a elipsoide, às vezes levemente curvada, vermelha quando madura; pirênio 6-sulcado longitudinalmente em secção transversal.

Material selecionado: Macau, RDS Estadual Ponta do Tubarão, 24.II.2009, fr., J.L. Costa-Lima 119 (HUEFS, UFRN). Mossoró, 20.I.1974, fl., D. Andrade-Lima 747571 (IPA).

Espécie com ocorrência nos estados do Ceará, Rio Grande do Norte, Pernambuco e Bahia, em áreas de caatinga (Loiola \& Costa-Lima 2014). No Rio Grande do Grande do Norte foi observada habitando a caatinga arbustiva hiperxerófila, em solo arenoso, com flores nos meses de outubro e fevereiro e com frutos em fevereiro e março.

Erythroxylum nummularia é uma espécie próxima a E. vacciniifolium, com a qual é comumente confundida. No entanto, pode ser diferenciada desta pela morfologia das estípulas e lâmina foliar. Erythroxylum nummularia apresenta estípulas com 1-2 mm de comprimento, 2-setulosas no ápice com coléteres vilosos e a lâmina foliar é obovada com ápice emarginado a obcordado; já E. vacciniifolium apresenta estípulas maiores (com 2-3,8 mm compr.), 3 -setulosas no ápice com coléteres inconspícuos e lâmina foliar elíptica a largo-elíptica com ápice agudo a retuso. 


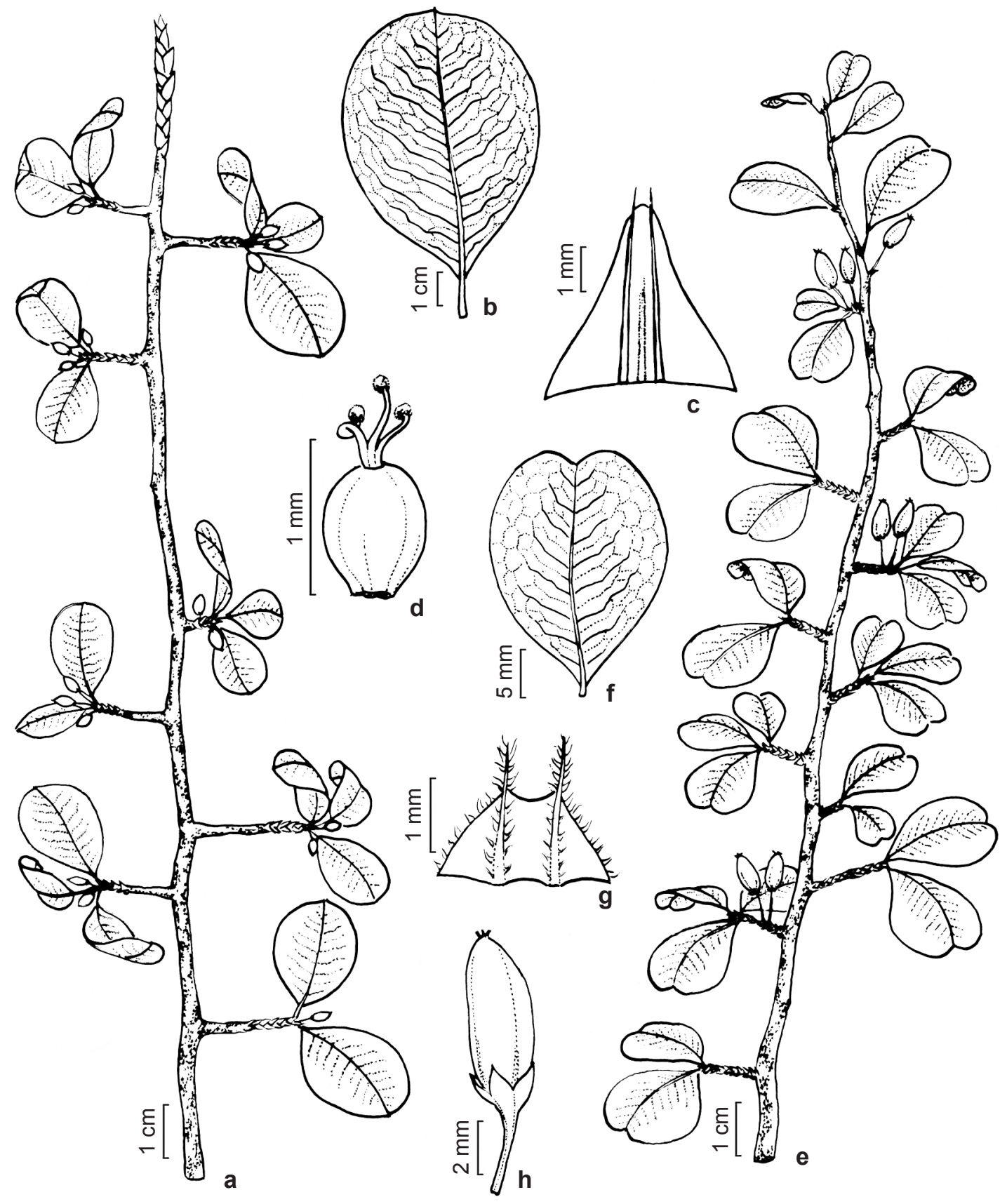

Figura 1 - a-d. Erythroxylum caatingae - a. aspecto geral do ramo com frutos; b. lâmina foliar; c. estípula, vista abaxial; d. ovário de flor brevistila (a-d Sarmento \& Assis 747). e-h. E. nummularia - e. aspecto geral do ramo com frutos; f. lâmina foliar; g. estípula, vista abaxial; h. drupa (e-h Costa-Lima 108).

Figure 1 -a-d. Erythroxylum caatingae - a. fruiting branch; b. leaf blade; c. stipule, ventral view; d. ovary from brevistylous flower (a-d Sarmento \& Assis 747). e-h. E. nummularia - e. fruiting branch; f. leaf blade; g. stipule, ventral view; h. drupe (e-h Costa-Lima 108).

4. Erythroxylum passerinum Mart., Beitr. Erythroxylon 106. 1840.

Fig. 2e-g

Arbustos, arvoretas ou árvores, 1,5-7 $\mathrm{m}$ alt.; ramos com ritidoma liso, lenticelas presentes. Estípulas 2-3,4 mm compr., estriadas longitudinalmente, triangulares, 3-setulosas, coléteres inconspícuos; catafilos laxamente distribuídos nos ramos. Lâmina foliar cartáceas, largo-elíptica a elíptica, raro obovada, 2-8,8 $\times$ $1,5-4,4 \mathrm{~cm}$, base aguda, margem plana, ápice 
agudo; venação secundária 10-14 pares, dispostos alternadamente; pecíolo 1-2,2 mm compr. Fascículos 1-5 flores; pedicelo 3-6,4 mm compr.; cálice com prefloração valvar, lobos $1-1,8 \times 0,8-1$ $\mathrm{mm}$, triangulares, ápice agudo a acuminado; pétala 3,2-4,4 mm compr., oblonga, margem inteira, côncava; tubo estaminal 1-1,2 mm compr.; flores brevistilas não observadas; flores longistilas: filetes opositissépalos 1,2-1,8 mm compr., alternissépalos 1,8-2,6 mm compr., anteras 0,5-0,7 ×0,4-0,5 mm, estiletes 2,5-4,2 mm compr., livres; ovário 1,5-2 $\times 0,9-1,2 \mathrm{~mm}$, ovoide a elipsoide. Drupa 7,4-10 $\times$ 4,3-6,5 mm, ovoide a elipsoide, vermelha quando madura; pirênio 6-sulcado longitudinalmente em secção transversal.

Material selecionado: Baía Formosa, RPPN Mata Estrela, 7.III.2011, fr., W.W. Thomas et al. 15283 (JPB). Canguaretama, 5.II.2011, fl., A.A. Roque 1262 (UFRN). Ceará-Mirim, Fazenda Diamante, 14.XII.2011, fl., J.G. Jardim et al. 6155 (UFRN). Extremoz, APA Jenipabu, 3.II.2011, fr., J.L. Costa-Lima et al. 329 (UFRN). Goianinha, Fazenda Nossa Senhora do Carmo, 12.II.2011, fr., J.L. Costa-Lima et al. 380 (UFRN). Macaíba, Escola Agrícola de Jundiaí, 1.III.2011, fr., J.L. Costa-Lima et al. 442 (UFP, UFRN). Natal, Parque Estadual Dunas do Natal, 1.II.2010, fl., J.L. Costa-Lima 288 (UFP, UFRN). Nísia Floresta, Floresta Nacional de Nísia Floresta, 24.IV.2003, fr., M.I.B. Loiola 783 (UFP, UFRN). Parnamirim, Hidrominas Santa Maria, 20.III.2006, fr., A. Ribeiro \& B. Colombo 120 (UFRN). São José de Mipibu, Fazenda Muriaé, 11.II.2011, fr., J.L. Costa-Lima et al. 357 (UFRN).

Espécie com distribuição na faixa litorânea da Paraíba ao Rio de Janeiro, em restinga (Loiola \& Costa-Lima 2014). Registrada aqui pela primeira vez no Rio Grande do Norte, encontrada na restinga arbóreo-arbustiva e nas florestas estacionais, onde pode ocorrer tanto na orla quanto no interior das florestas, assim como nas "ilhas de vegetação" dos tabuleiros litorâneos (vegetação savânica). Pode ser encontrada fértil durante a maior parte do ano.

Essa espécie pode ser confundida com Erythroxylum simonis, principalmente pelo hábito e morfologia foliar, mas podem ser diferenciadas pelos coléteres nas estípulas, consistência da lâmina foliar, relação do tamanho entre o tubo estaminal e os lobos do cálice e pela secção transversal do pirênio. Erythroxylum passerinum apresenta estípulas com coléteres inconspícuos ( $v S$. conspícuos e fimbriolados em E simonis), lâmina foliar cartácea ( $v s$. membranácea), tubo estaminal menor que os lobos do cálice ( $v s$. maior) e pirênio 6-sulcado longitudinalmente em secção transversal (vs. cilíndrico).
5. Erythroxylum pungens O.E.Schulz in Engler., Pflanzenr. 4(134): 49. $1907 . \quad$ Fig. 2a-d

Arbustos a arvoretas, 1,5-3 m alt.; ramos com ritidoma liso, lenticelas presentes. Estípulas 1-2 mm compr., estriadas longitudinalmente, triangulares, 3-setulosas, coléteres fimbriolados; catafilos adensados formando braquiblastos. Lâmina foliar cartácea, oblonga a obovada, raro suborbicular, $1-4,2 \times 1-2,6 \mathrm{~cm}$, base aguda, margem plana, ápice obtuso a retuso; venação secundária 10-14 pares, dispostos alternadamente; pecíolo 1-4,8 mm compr. Fascículos 1-3 flores; pedicelo (3)6-15 mm compr.; cálice com prefloração valvar, lobos 1-1,5 × 1-1,2 $\mathrm{mm}$, oblongos a triangulares, ápice acuminado; pétala 2,8-3,5 mm compr., obovada, margem inteira, plana; tubo estaminal 0,8-1,4 mm compr.; flores brevistilas: filetes 2,6-4,5 mm compr., anteras $0,4-0,5 \times 0,3-0,5 \mathrm{~mm}$, elípticas, estiletes 1,6-2 mm compr., livres; flores longistilas: filetes opositissépalos 2-2,2 mm compr., alternissépalos 2-2,6 mm compr., anteras 0,4-0,5 × 0,4-0,5 mm, estiletes 3,5-4,2 mm compr., livres; ovário 1,5-2,2 $\times 0,8-1,4 \mathrm{~mm}$, elipsoide. Drupa 5,7-12 × 3,5-5 $\mathrm{mm}$, elipsoide, enegrecida quando madura; pirênio cilíndrico em secção transversal.

Material selecionado: $S$. loc., nordeste do Rio Grande do Norte, 26.I.1961, fl., A. Castellanos 23007 (R). Apodi, Lajedo Soledade, 11.X.2009, fr., J.L. Costa-Lima 245 (UFRN). Baraúna, Chapada do Apodi, 30.I.2010, fr., E. Silveira et al. (EAC 46805). Jandaíra, Assentamento Guarapes, 5.IX.2011, fl. e fr., J.L. Costa-Lima 550 (UFRN). Serra Negra do Norte, Estação Ecológica do Seridó, 25.III.2012, fr., A.A. Roque et al. 1332 (UFRN).

Ocorre nos estados da Bahia, Ceará, Maranhão, Paraíba, Pernambuco e Piauí em áreas de caatinga (Loiola \& Costa-Lima 2014). No Rio Grande do Norte, novo registro, é comumente encontrada em áreas de caatinga hipo e hiperxerófila em solo arenoso, substrato calcário ou em afloramentos graníticos. Espécie com flores em setembro e janeiro e com frutos em setembro, outubro e janeiro.

Erythroxylum pungens é facilmente reconhecida pelas estípulas com coléteres fimbriolados, presença de braquiblastos, flores concentradas no ápice dos braquiblastos e com pedicelos longos, drupa enegrecida quando madura e pirênio cilíndrico em secção transversal.

6. Erythroxylum revolutum Mart., Beitr. Erythroxylon 71. 1840 . Fig. 2h-k

Arbustos, 1,5-3 m alt.; ramos com ritidoma liso, lenticelas presentes. Estípulas 1,5-2,8 mm compr., estriadas longitudinalmente, triangulares, 


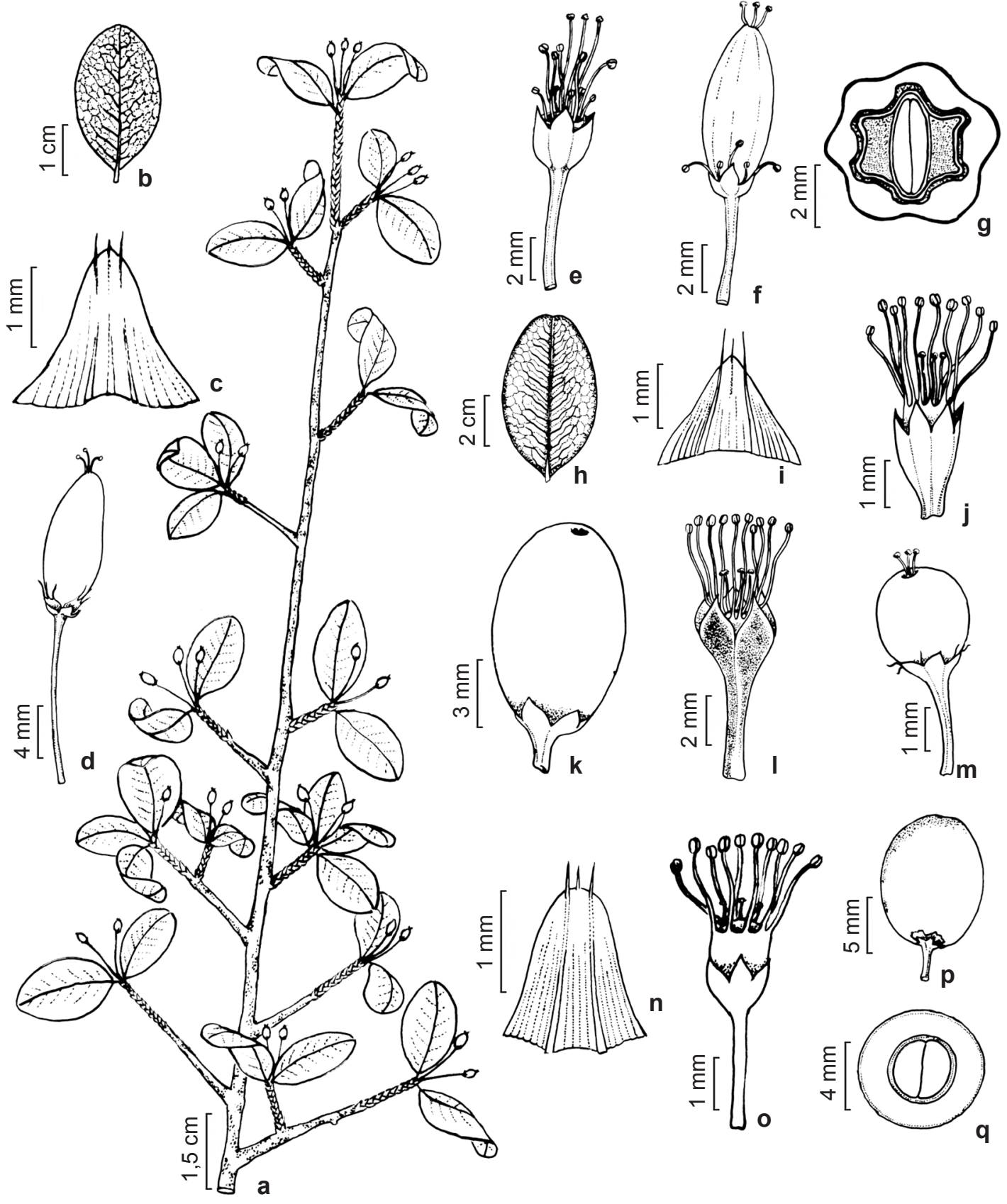

Figura 2 - a-d. Erythroxylum pungens - a. aspecto geral do ramo com frutos; b. lâmina foliar; c. estípula, vista abaxial; d. drupa (a-d Costa-Lima 550). e-g. E. passerinum - e. flor longistila, corola removida; f. drupa; g. secção transversal da drupa (e Costa-Lima 289; f-g Costa-Lima 288). h-k. E. revolutum - h. lâmina foliar; i. estípula, vista abaxial; j. flor brevistila, corola removida; k. drupa (h-j Costa-Lima \& Marinho 458; k Costa-Lima \& Andrade 497). 1-m. E. rimosum -1. flor brevistila, corola removida; m. drupa (1 Costa-Lima et al. 439; m Costa-Lima 278). n-q. E. simonis - n. estípula, vista abaxial; o. flor brevistila, corola removida; p. drupa; q. secção transversal da drupa (n-q Costa-Lima 310).

Figure 2 - a-d. Erythroxylum pungens - a. fruiting branch; b. leaf blade; c. stipule, ventral view; d. drupe (a-d Costa-Lima 550). e-g. E. passerinum - e. longistylous flower corolla removed; f. drupe; g. cross section of the drupe (e Costa-Lima 289; f-g Costa-Lima 288). h-k. E. revolutum - h. leaf blade; i. stipule, ventral view; j. brevistylous flower with corolla removed; k. drupe (h-j Costa-Lima \& Marinho 458; $\mathrm{k}$ Costa-Lima \& Andrade 497). 1-m. E. rimosum - 1. brevistylous flower with corolla removed; m. drupe (1 CostaLima et al. 439; m Costa-Lima 278). n-q. E. simonis - n. stipule, ventral view; o. brevistylous flower with corolla removed; p. drupe; q. cross section of the drupe (n-q Costa-Lima 310). 
3-setulosas, coléteres inconspícuos; catafilos laxamente distribuídos nos ramos. Lâmina foliar cartácea, oblonga, obovada a ovada, raro elíptica, $1,6-6(-12) \times 1-3,5(7) \mathrm{cm}$, base aguda a obtusa, margem frequentemente revoluta, raro plana, ápice agudo, obtuso ou retuso; venação secundária 8-14 pares, dispostos alternadamente; pecíolo 2-6,2 mm compr. Fascículos 1-3 flores; pedicelo 0,5-2 $\mathrm{mm}$ compr.; cálice com prefloração valvar, lobos $0,8-1,2 \times 0,8-1 \mathrm{~mm}$, triangulares, ápice agudo a acuminado; pétala $2-5 \mathrm{~mm}$ compr., oblonga a obovada, margem inteira a levemente crenada, côncava; tubo estaminal $0,8-2,2 \mathrm{~mm}$ compr.; flores brevistilas: filetes $3-5,5 \mathrm{~mm}$ compr., anteras $0,3-0,5 \times$ ca. $0,4 \mathrm{~mm}$, estiletes $1,6-2,3 \mathrm{~mm}$ compr., livres; flores longistilas: filetes opositissépalos 1,5-2 mm compr., alternissépalos 1,8-3,2 mm compr., anteras $0,5-0,7 \times 0,4-0,5 \mathrm{~mm}$, estiletes 3-4,6 mm compr., livres, verdes; ovário 1-1,4 $\times$ $0,6-0,8 \mathrm{~mm}$, obovoide. Drupa 7-10 × 4,2-6,6 mm, elipsoide a largo-elipsoide, enegrecida quando madura; pirênio cilíndrico em secção transversal. Material selecionado: Alexandria, Serra da Barriguda, 31.VII.2011, fr., J.L. Costa-Lima \& M. Andrade 497 (UFP, UFRN). Bento Fernandes, Serra da Cachoeira do Sapo, 8.II.2012, fl., J.L. Costa-Lima et al. 610 (UFP, UFRN). Natal, Redinha, 3.V.2011, fl., J.L. Costa-Lima \& A. Marinho 458 (UFP, UFRN). João Câmara, Fazenda Cauaçu, 13.III.2011, fl., J.G. Jardim et al. 5935 (UFRN). Jucurutu, RPPN Stoessel de Britto, 27.XII.2007, fl., A.A. Roque 360 (JPB, UFRN). Rio do Fogo, margem do rio Punaú, 31.III.2012, fr., J.G. Jardim et al. 6176 (UFRN). Serrinha dos Pintos, Sítio Ch. Raimundo, 2.III.2006, fl., R.T. Queiroz et al. 617 (TEPB, UFRN).

Segundo Loiola \& Costa-Lima (2014), essa espécie tem registro apenas para a Região Nordeste (Alagoas, Bahia, Ceará, Paraíba, Pernambuco, Piauí e Sergipe), em vegetação de caatinga. No Rio Grande do Norte, onde é registrada pela primeira vez, é amplamente distribuída e está mais frequentemente associada às formações das Caatingas, ocorrendo tanto em hábitats serranos com afloramentos granito-gnáissicos, quanto em áreas de caatinga hiperxerófila em solo arenoso, em geral formando densas populações. Destaca-se aqui o registro inédito para as formações do Domínio da Mata Atlântica, onde foi registrada em floresta estacional semidecídua e em vegetação de restinga. Foi encontrada com flores em fevereiro, março, maio e dezembro e com frutos em julho.

Pode ser confundida com Erythroxylum rimosum pelo aspecto geral dos ramos e morfologia da lâmina foliar, mas pode ser diferenciada dessa pelo ritidoma liso, flores subsésseis, cálice com prefloração valvar com lobos triangulares e fruto enegrecido quando maduro, enquanto E. rimosum apresenta ritidoma consistindo em lâminas papiráceas, flores pediceladas, cálice com prefloração contorcida com lobos oblongos e fruto vermelho quando maduro.

7. Erythroxylum rimosum O.E.Schulz in Engler, Pflanzenr. 4(134): 53. $1907 . \quad$ Fig. 21-m

Subarbustos a arbustos, 0,5-1,5 m alt.; ramos com ritidoma em lâminas papiráceas, lenticelas presentes. Estípulas 1,3-3 mm compr., estriadas longitudinalmente, triangulares, 3-setulosas, coléteres inconspícuos; catafilos laxamente distribuídos nos ramos. Lâmina foliar subcoriácea a coriácea, oblonga a obovada, raro suborbicular, 1,6-8,5 × 1,3-5,5 cm, base aguda, margem plana a levemente revoluta, obtuso a retuso; venação secundária 10-14 pares, dispostos alternadamente; pecíolo 1-3,8 mm compr. Fascículos 1-4 flores; pedicelo 3,3-8,5 mm compr.; cálice com prefloração contorcida, lobos 1-2,3 × 1,3-2 mm, oblongos, ápice cuspidado; pétala 4-5,3 $\mathrm{mm}$ compr., oblonga, margem inteira, côncava; tubo estaminal $0,8-1,5 \mathrm{~mm}$ compr.; flores brevistilas: filetes 3,5-4,8 mm compr., anteras $0,4-0,5 \times 0,4-0,5$ $\mathrm{mm}$, , estiletes $1,3-1,8 \mathrm{~mm}$ compr., livres; flores longistilas: filetes opositissépalos $0,7-1,5 \mathrm{~mm}$ compr., alternissépalos 1,4-2,5 mm compr., anteras 0,4-0,6 $\times 0,4-0,5 \mathrm{~mm}$, estiletes $2,2-3,5 \mathrm{~mm}$ compr., livres; ovário 1-1,8 × 0,7-1,4 mm, obovoide a elipsoide. Drupa 6,5-8,8 × 4,3-5,6 mm, elipsoide a ovoide, vermelha quando madura; pirênio cilíndrico em secção transversal.

Material selecionado: Ceará-Mirim, Fazenda Diamante, 14.XII.2011, fr., J.G. Jardim et al. 6156 (UFRN). Coronel João Pessoa, Serra São José, 19.VII.1991, fr., M.A. Figueiredo et al. 248 (EAC, MOSS). Macaíba, Escola Agrícola de Jundiaí, 1.III.2011, fr., J.L. Costa-Lima et al. 439 (UFP, UFRN). Natal, Parque Estadual Dunas do Natal, 3.III.2011, fr., J.L. Costa-Lima \& A. Morais 447 (UFP, UFRN). Parnamirim, Parque Industrial, 10.I.2010, fl., J.L. Costa-Lima 278 (HUEFS, MOSS, UFRN). Rio do Fogo, Punaú, 5.III.2009, fr., A.C.P. Oliveira et al. 944 (UFRN). Tibau do Sul, Santuário Ecológico de Pipa, 28.VII.1994, fl. e fr., M.L.L. Martins 454 (IPA).

Restrita ao Nordeste do Brasil, com registros confirmados nos estados do Ceará, Paraíba, Piauí, Rio Grande do Norte e Sergipe, em vegetação savânica (restinga, cerrado e carrasco) (Loiola et al. 2007; Loiola \& Costa-Lima 2014). No Rio Grande do Norte apresenta distribuição disjunta nas formações do Domínio da Floresta Atlântica, onde foi registrada em floresta estacional em áreas serranas no extremo oeste e nos tabuleiros litorâneos 
do Litoral Oriental, frequentemente associada a solos sedimentares da Formação Barreiras. Floresce e frutifica ao longo de todo o ano.

Similar a Erythroxylum revolutum, sendo os caracteres para diferenciação dessas expostos nos comentários dessa última espécie.

Erythroxylum rimosum foi inicialmente posicionada por Schulz (1907) em Erythroxylum sect. Rhabdophyllum, que engloba as espécies com estípulas estriadas longitudinalmente e cálice com prefloração valvar e lobos triangulares, porém a análise de espécimes em campo e depositados em diversos herbários mostrou que essa espécie apresenta como características marcantes o cálice com prefloração contorcida e lobos oblongos, as quais permitem seu posicionamento em Erythroxylum sect. Macrocalyx O.E.Schulz.

\section{Erythroxylum simonis Plowman, Brittonia} 38(3): 189. 1986.

Fig. 2n-q

Subarbustos a arbustos, 1,5-5 m alt.; ramos com ritidoma liso, lenticelas presentes. Estípulas 1,1-2,7 mm compr., estriadas longitudinalmente, triangulares, 3-setulosas, coléteres fimbriolados; catafilos laxamente distribuídos nos ramos. Lâmina foliar membranácea, elíptica a estreito-elíptica, 1,4-6,3 × 1,2-2,8 cm, base aguda, margem plana, ápice acuminado a agudo; venação secundária 8-16 pares, dispostos alternadamente; pecíolo 1,3-3,8 mm compr. Fascículos 1-5 flores; pedicelo 2,5-6,6 mm compr.; cálice com prefloração valvar, lobos 0,6-1 × 0,7-1 mm, triangulares, ápice agudo; pétala 2,2-3,5 mm compr., oblonga, margem inteira, côncava; tubo estaminal 1-1,4 $\mathrm{mm}$ compr.; flores brevistilas: filetes $1-1,5 \mathrm{~mm}$ compr., anteras 0,4-0,5 × 0,4-0,5 mm, estiletes 0,5-0,7 mm compr., livres; flores longistilas: filetes opositissépalos $0,4-0,7 \mathrm{~mm}$ compr., alternissépalos $0,6-1 \mathrm{~mm}$ compr., anteras $0,4-0,5$ $\times 0,4-0,5 \mathrm{~mm}$, estiletes $1,5-2,0 \mathrm{~mm}$ compr., livres; ovário 1-1,4 × 0,7-1,2 mm, obovoide a elipsoide. Drupa 7,4-9,5 × 6-7,8 mm, obovoide a elipsoide, vermelha a atropurpúrea quando madura; pirênio cilíndrico em secção transversal.

Material selecionado: Baía Formosa, Mata Estrela, 10.IX.2011, fr., J.L. Costa-Lima \& W. São-Mateus 560 (UFRN). Ceará-Mirim, Fazenda Diamante, 18.VIII.2011, fl., J.G. Jardim et al. 6064 (UFRN). Macaíba, Escola Agrícola de Jundiaí, 1.III.2011, fl. e fr., J.L. Costa-Lima et al. 443 (UFP, UFRN). Natal, Parque Estadual Dunas do Natal, 22.V.2010, fl. e fr., J.L. Costa-Lima 310 (UFP, UFRN). Parnamirim, Mata do Jiqui, 25.III.2009, fr., D.F.F. Mól 47 (HUEFS, UFRN).
Espécie restrita ao Nordeste, com registros para os estados do Ceará, Paraíba, Pernambuco e Sergipe, encontrada habitando as florestas úmidas do litoral ou ainda os ambientes florestados do interior, localmente conhecidos como "brejos de altitude" (Loiola et al. 2007; Loiola \& Costa-Lima 2014). Novo registro no Rio Grande do Norte, onde é encontrada apenas nos ambientes florestados do Litoral Oriental, como na restinga arbóreoarbustiva e nas florestas estacionais semidecíduas, onde habita o interior das matas. Encontra-se fértil durante todo o ano.

Pode ser confundida com E. passerinum, espécie comumente simpátrida, porém os caracteres para diferenciá-las foram mencionadas nos comentários dessa última espécie.

9. Erythroxylum squamatum Sw., Prod. 75. 1788. Arvoretas, ca. $3 \mathrm{~m}$ alt.; ramos com ritidoma liso, lenticelas ausentes. Estípulas 1,8-2,5 mm compr., estriadas longitudinalmente, estrias mais evidentes nas estípulas juvenis, triangulares, 3-setulosas, coléteres inconspícuos; catafilos adensados formando braquiblastos. Lâmina foliar cartácea, elíptica a largo-elíptica, 10-18 $\times$ 4,2-6 cm, base cuneada, margem plana, ápice cuspidado; venação secundária 10-12 pares, dispostos alternadamente; pecíolo 1,5-7 $\mathrm{mm}$ compr. Fascículos 1-3 flores; pedicelo 6,4-8,2 mm compr.; cálice com prefloração valvar, lobos 1,7-2 $\times$ 0,5-1 mm, estreito-triangulares, ápice agudo a acuminado; pétala 3,2-4,5 mm compr., oblonga, margem inteira, côncava; tubo estaminal 0,8-1,2 mm compr.; flores brevistilas: não observadas; flores longistilas: filetes opositissépalos 0,6-1 mm compr., alternissépalos $0,8-1,5 \mathrm{~mm}$ compr., anteras 1,4-1,8 × 0,6-0,8 mm, estiletes $2-3,8 \mathrm{~mm}$ compr., livres; ovário 1,4-1,8 ×0,6-0,8 mm, ovoide. Drupa $7-12 \times 0,9-1,5 \mathrm{~mm}$, elipsoide, vermelha quando madura; pirênio 6-sulcado longitudinalmente em secção transversal.

Material examinado: Canguaretama, BR-101 após a divisa dos estados, 11.V.2012, fr., J.G. Jardim et al. 6262 (UFP, UFRN).

Material examinado adicional: BRASIL. PERNAMBUCO: Goiana, 27.XII.1967, fl., D. AndradeLima 67-5171 (IPA).

Apresenta distribuição ampla, ocorrendo desde as Antilhas à América do Sul e no Brasil ocorre nas matas úmidas da Amazônia e Floresta Atlântica (Plowman \& Hensold 2004; Loiola \& Costa-Lima 2014). No Rio Grande do Norte é 
registrada pela primeira vez, onde foi encontrada em mata ciliar numa área de floresta estacional semidecídua no Litoral Oriental, com frutos no mês de maio.

É prontamente reconhecida pela lâmina foliar com ápice cuspidado e pelos fascículos concentrados no ápice dos braquiblastos.

10. Erythroxylum subrotundum A.St.-Hil., P1. usuel. bras. 3: t. 69. 1828.

Arbustos a arvoretas, 2-3 m alt.; ramos com ritidoma liso, lenticelas presentes. Estípulas 1-2,5 mm compr., lisas, triangulares, 2-setulosas, coléteres vilosos; catafilos laxamente distribuídos nos ramos. Lâmina foliar membranácea, obovada a suborbicular, 2-5,6 $\times$ 0,6-3,4 cm, base atenuada, margem plana, ápice obtuso, às vezes apiculado; venação secundária 5-7 pares, dispostos alternadamente; pecíolo 1,5-8(-12) × 1-2,6 mm compr. Fascículos 1-5 flores; pedicelo 3-4,5 mm compr.; cálice com prefloração valvar, lobos 1,2-2 × 0,5-1 mm, estreito-triangulares, ápice acuminado; pétala 2,8-4 mm compr., oblonga a oboval, margem inteira, côncava; tubo estaminal 0,8-1,8 mm compr.; flores brevistilas: filetes $1-2$ mm compr., anteras $0,4-0,5 \times$ ca. $0,4 \mathrm{~mm}$, estiletes 0,5-1,2 mm compr., livres; flores longistilas não observadas; ovário 0,8-1,6 × 0,5-1 mm, obovoide. Drupa 7,5-11 × 4-6,2 mm, obovoide a elipsoide, vermelha quando madura; pirênio 6-sulcado longitudinalmente em secção transversal.

Material selecionado: Bento Fernandes, Serra da Cachoeira do Sapo, 8.II.2012, fl., J.L. Costa-Lima et al. 612 (UFRN-2). Canguaretama, 24.II.1980, fl., O.F. Oliveira et al. 1667 (MOSS). Cerro Corá, 28.III.1982, fr., A. Fernandes \& E. Matos (EAC 11155, UFRN 12011). São Vicente, 1.III.1980, fl., O.F. Oliveira et al. 147 (MOSS).

Tem distribuição na Bolívia e Brasil, nesse último ocorre nas porções leste, do Rio de Janeiro ao Ceará, e central, no Distrito Federal e Goiás (Plowman \& Hensold 2004; Loiola \& Costa-Lima 2014). No Rio Grande do Norte foi registrada vegetando em áreas de caatinga hiperxerófila e florestas estacionais semidecíduas. Encontrada com flores nos meses de janeiro, fevereiro e março, e com frutos em março.

Pode ser diferenciada das demais espécies que ocorrem no Rio Grande do Norte pelas folhas membranáceas, frequentemente obovadas, estípulas lisas e com coléteres vilosos e pirênio 6-sulcado longitudinalmente em secção transversal.
11. Erythroxylum vacciniifolium Mart., Beitr. Erythroxylon 71. 1840.

Arbustos, 1-2 m alt.; ramos com ritidoma liso, lenticelas presentes. Estípulas 2-3,8 mm compr., lisas, triangulares, 3-setulosas, coléteres inconspícuos; catafilos laxamente distribuídos nos ramos. Lâmina foliar cartácea, elíptica a largoelíptica, $1,2-8,1 \times 0,7-3,4 \mathrm{~cm}$, base cuneada, margem plana, ápice agudo a retuso; venação secundária 8-10 pares, dispostos alternadamente; pecíolo 0,6-2,2 mm compr. Fascículos 1-4 flores; pedicelo 1,5-3 mm compr.; cálice com prefloração valvar, lobos $0,6-1,2 \times 0,5-1 \mathrm{~mm}$, largo-triangulares, ápice agudo; pétala 2,3-3 mm compr., oblonga, margem inteira, côncava; tubo estaminal $0,8-1 \mathrm{~mm}$ compr.; flores brevistilas: filetes 2,5-3,2 mm compr., anteras $0,3-0,5 \times$ $0,3-0,5 \mathrm{~mm}$, estiletes $0,8-1 \mathrm{~mm}$ compr., livres; flores longistilas não observadas; ovário $0,8-1,2$ $\times 0,6-1 \mathrm{~mm}$, ovoide a elipsoide. Drupa 7-10 $\times$ $3,6-5,4 \mathrm{~mm}$, elipsoide, vermelha quando madura; pirênio 6-sulcado longitudinalmente em secção transversal.

Material selecionado: Martins, ida para Serrinha dos Pintos, 2.III.2006, fr., R.T. Queiroz 609 (IPA, TEPB, UFRN). Mossoró, Alagoinha, 26.III.2008, fr., R.C. Oliveira et al. 2096 (MOSS).

Material examinado adicional: BRASIL. CEARÁ: S. loc., Serra de Baturité, 3.II.1939, fl, J. Eugenio 510 (RB). Meruoca, 4.I.2000, fl., A. Fernandes (EAC 28800).

Ocorre do Rio Grande do Sul ao Ceará, nos mais variados hábitats (Plowman 1987; Loiola \& Costa-Lima 2014). Trata-se de um novo registro da espécie no Rio Grande do Norte, com registro no extremo oeste, em floresta estacional semidecídua interiorana e em caatinga, em elevações que variam de 100-720 m. Foi encontrada com frutos apenas no mês de março.

Morfologicamente relacionada a $E$. nummularia, porém os caracteres para distingui-las já foram apresentados na descrição desta espécie.

\section{Agradecimentos}

Ao INCT Virtual da Flora e Fungos do Brasil pela bolsa concedida ao primeiro autor (processo 372532/2009-8) durante o período de realização deste trabalho; aos curadores e funcionários dos herbários visitados pelo acesso aos acervos e/ ou pela disponibilização de imagens; à M.Sc. Alessandra Jardim e ao Dr. Leonardo Versieux pelas sugestões ao manuscrito. 


\section{Referências}

Amaral Jr., A. 1976. Erythroxylum campinense (Erythroxylaceae), espécie nova da Amazônia. Acta Amazonica 6: 213-214.

Amaral Jr., A. 1980. Erythroxylaceae. In: Reitz, R. (ed.). Flora Ilustrada Catarinense. Parte I, fasc. ERIT: 1-64.

Amaral Jr., A. 1990. Uma nova espécie de Erythroxylum P. Browne (Erythroxylaceae) do estado do Espírito Santo, Brasil. Naturalia 15: 147-151.

Amaral Jr., A. 1996. Erythroxylaceae. In: Melo, M.M.R.F. et al. (eds.). Flora fanerogâmica da Ilha do Cardoso 4: 71-78.

APG III. 2009. An update of the Angiosperm Phylogeny Group classification for the orders and families of flowering plants: APG III. Botanical Journal of the Linnean Society 161: 105-121.

Barbosa, A.V.G. \& Amaral, A. 2001. Erythroxylaceae. In: Rizzo, J.A. (ed.). Flora dos estados de Goiás e Tocantins 29: 9-73.

Brummitt, R.K. \& Powell, C.E. 1992. Authors of plant names. Royal Botanic Gardens, Kew. 736p.

Costa-Lima, J.L. \& Alves, M. 2013. A new species of Erythroxylum (Erythroxylaceae) from the Brazilian Atlantic Forest. Phytotaxa 141: 55-60.

Costa-Lima, J.L.; Loiola, M.I.B.; Cordeiro, L.S. \& Alves, M. 2013. Erythroxylaceae. In: Prata, A.P.N.; Amaral, M.C.E.; Farias, M.C.V. \& Alves, M.V. (eds.). Flora de Sergipe 1: 233-247.

Costa-Lima, J.L.; Loiola, M.I.B. \& Alves, M. 2014. A new species of Erythroxylum (Erythroxylaceae) from northeastern Brazil. Brittonia 66: 60-64.

Daly, D. 2004. Erythroxylaceae. In: Smith, N.; Mori, S.A.; Henderson, A.; Stevenson, D.W. \& Heald, S.V. (eds.). Flowering plants of the Neotropics. The New York Botanical Garden, Princeton University Press, New York. Pp. 143-145.

Davis, C.C.; Webb, C.O.; Wurdack, K.J.; Jaramillo, C.A. \& Donoghue, M.J. 2005. Explosive radiation of Malphighiales supports a Mid-Cretaceous origin of modern tropical rain forests. The American Naturalist 165: 36-65.

Dubs, B. 1998. Erythroxylaceae. Prodromus Florae Matogrossensis. Pt. 1. 3: 94-97.

Huber, J.E. 1909. Materiaes para a flora amazonica VII. Boletim do Museu Paraense de História Natural e Ethnographia 5: 414-422.

Judd, W.S.; Campbell, C.S.; Kellogg, E.A. \& Stevens, P.F. 1999. Plant systematics: a phylogenetic approach. Sinauer Associates, Massachusetts. 464p.

Judd, W.S. \& Olmstaed, R.G. 2004. A survey of tricolpate (eudicot) phylogenetic relationships. American Journal of Botany 91: 1627-1644.

Kuhlmann, J. \& Rodrigues, W.A. 1957. Novitates Florae Amazonicae. Publicações do Instituto Nacional de Pesquisas da Amazônia, Série Botânica 5: 3.
Loiola, M.I.B. 2004. Flora de Grão-Mogol, Minas Gerais: Erythroxylaceae. Boletim de Botânica da Universidade de São Paulo 22: 101-108.

Loiola, M.I.B.; Agra, M.F.; Baracho, G.S. \& Queiroz, R.T. 2007. Flora da Paraíba, Brasil: Erythroxylaceae Kunth. Acta Botanica Brasilica 21: 473-487.

Loiola, M.I.B. \& Sales, M.F. 2008. Two new species of Erythroxylum sect. Rhabdophyllum (Erythroxylaceae) from north-eastern Brazil. Kew Bulletin 63: 655-659.

Loiola, M.I.B. \& Gomes, J.M.O. 2009. Erythroxylaceae. In: Alves, M.; Araújo, M.F.; Maciel, J.R. \& Martins, S. (eds.). Flora de Mirandiba. Associação Plantas do Nordeste, Recife. Pp. 146-148.

Loiola, M.I.B. \& Sales, M.F. 2012. Erythroxylum ayrtonianum (Erythroxylaceae): a new species from Brazil. Novon 22: 48-50.

Loiola, M.I.B. \& Costa-Lima, J.L. 2014. Erythroxylaceae. In: Lista de espécies da flora do Brasil. Jardim Botânico do Rio de Janeiro. Disponível em $<$ http://floradobrasil.jbrj.gov.br/jabot/floradobrasil/ FB111>. Acesso em fevereiro 2014.

Martius, K.F.P. 1843. Beiträge zur Kenntniss der Gattung Erythroxylon. Abhandlungen der MathematischPhysikalischen Classe der Königlich Bayerischen Akademie der Wissenschaften 3: 280-410.

Mendonça, J.O., Cervi, A.C. \& Guimarães, O.A. 1998. O gênero Erythroxylum P. Browne (Erythroxylaceae) do estado do Paraná, Brasil. Brazilian Archives of Biology and Technology 41: 349-358.

Mendonça, J.O. \& Amaral Jr, A. 2002a. Erythroxylaceae. In: Cavalcanti, T.B. \& Ramos, A.E. (coords.). Flora do Distrito Federal 2: 53-72.

Mendonça, J.O. \& Amaral Jr., A. 2002b. Erythroxylaceae. In: Wanderley, M.G.L.; Shepherd, G.J. \& Giulietti, A.M. (coords.). Flora fanerogâmica do estado de São Paulo 2: 107-120.

Mori, S.A.; Silva, L.A.M.; Lisboa, G. \& Corandin, L. 1989. Manual de manejo do herbário fanerogâmico. $2^{\mathrm{a}}$ ed. Centro de Pesquisas do Cacau, Ilhéus. 104p.

Patrício, M.C.B. \& Pirani, J.R. 2002. Flora da Serra do Cipó, Minas Gerais: Erythroxylaceae. Boletim de Botânica da Universidade de São Paulo 20: 53-61.

Peyritsch, J. 1878. Erythroxylaceae. In: Martius, K.F.P. \& Eichler, A.G. (eds.). Flora brasiliensis 12: 125-180.

Plowman, T.C. 1983. New species of Erythroxylum from Brazil and Venezuela. Botanical Museum Leaflets 29: 273-290.

Plowman, T.C. 1984. New taxa of Erythroxylum (Erythroxylaceae) from the Amazon Basin. Acta Amazonica 14(Supl): 117-143.

Plowman, T.C. 1986. Four new species of Erythroxylum (Erythroxylaceae) from northeastern Brazil. Brittonia 38: 189-200. 
Plowman, T.C. 1987. Ten new species of Erythroxylum (Erythroxylaceae) from Bahia, Brazil. Fieldiana, Botany 19: 1-41.

Plowman, T.C. 1988. New taxa of Erythroxylum (Erythroxylaceae) from the Venezuelan Guayana. Brittonia 40: 256-268.

Plowman, T.C. \& Berry, P.E. 1999. Erythroxylaceae. In: Steyermark, J.A.; Berry, P.E.; Holst, B. \& Yatskievych, K. (eds.). Flora of Venezuelana Guayana 5: 59-71.

Plowman, T.C. \& Hensold, N. 2004. Names, types and distribution of neotropical species of Erythroxylum (Erythroxylaceae). Brittonia 56: 1-53.

Prance, G.T. 2006. Flora da Reserva Ducke, Amazonas, Brasil: Erythroxylaceae. Rodriguésia 57: 189-191.

Radford, A.E.; Dickison, W.C.; Massey, J.R. \& Bell, C.R. 1974. Vascular plant systematics. Harper \& Row, New York. 891p.

Savolainen, V.; Chase, M.W.; Hoot, S.B.; Morton, C.M.; Soltis, D.E.; Bayer, C.; Fay, M.F.; Bruijn, A.Y.; Sullivan, S. \& Qiu, Y-L. 2000. Phylogenetics of flowering plants based on combined analysis of plastid $a t p B$ and $r b c L$ gene sequences. Systematic Biology 49: 306-362.

Schulz, O.E. 1907. Erythroxylaceae. In: Engler, A. (ed.). Das Pflanzenreich 4: 1-176.

Schwarzbach, A.E. \& Ricklefs, R.E. 2000. Systematic affinities of Rhizophoraceae and Anisophylleaceae, and intergeneric relationships within Rhizophoraceae, based on chloroplast
DNA, nuclear ribosomal DNA, and morphology. American Journal of Botany 87: 547-564.

Setoguchi, H.; Kosuge, K. \& Tobe, H. 1999. Molecular phylogeny of Rhizophoraceae based on $r b c L$ gene sequences. Journal of Plant Research 112: 443-455.

Sobral, M. 1987. Erythroxylum (Erythroxylaceae) no Rio Grande do Sul. Pesquisas, Série Botânica 38: 7-42.

Soltis, D.E.; Soltis, P.S.; Chase, M.W.; Mort., M.E.; Albach, D.C.; Zanis, M.; Savolainen, V.; Hahn, W.H.; Hoot, S.B.; Fay, M.F.; Axtell, M.; Swensen, S.M.; Prince, L.M.; Kress, W.J.; Nixon, K.C. \& Farris, J.S. 2000. Angiosperm phylogeny inferred form $18 \mathrm{~S}$ rDNA, $r b c L$, and $a t p B$ sequences. Botanical Journal of the Linnean Society 133: 381-461.

Stearn, W.T. 1992. Botanical latin. $4^{\text {th }}$ ed. David \& Charles Book, Redwood Press, England Ltd., London. 546p.

Stevens, P.F. 2012. Angiosperm Phylogeny Website. Version 13, July 2012. Disponível em <http://www. mobot.org/MOBOT/research/APweb/>. Acesso em fevereiro 2014.

Thiers, B. 2013. [continuously updated]. Index Herbariorum: a global directory of public herbaria and associated staff. New York Botanical Gardens Virtual Herbarium. Disponível em <http:// sweetgum.nybg.org/ih>. Acesso em fevereiro 2014.

Zappi, D.C. 1995. Erythroxylaceae. In: B.L. Stannard (ed.). Flora of the Pico das Almas, Chapada Diamantina, Bahia, Brazil. Royal Botanic Gardens. Kew. Pp. 297-299.

\section{Índice de exsicatas}

Almeida, E.B.: 328 (7). Andrade-Lima, D.: 67-5171 (9), 74-7571 (3). Antunes, M.M.: EAC 18701 (4). Castellanos, A.: 23007 (5). Carauta, P.: 1700 (3). Cestaro, L.A.: 00-19 (8), 01-38 (7), 99-150 (8), 99-154 (8). Costa-Lima, J.L.: 76 (4), 108 (3), 119 (3), 245 (5), 278 (7), 288 (4), 289 (4), 298 (8), 299 (4), 309 (7), 310 (8), 329 (4), 357 (4), 380 (4), 439 (7), 442 (4), 443 (8), 447 (7), 449 (7), 458 (6), 491 (6), 497 (6), 550 (5), 560 (8), 610 (6), 612 (10). Emerich, M.: R 183120 (3). Falconi, V.V.: 10 (1). Félix, L.P.: 5584 (6), 10330 (6). Fernandes, A.: EAC 11155 (10), EAC 11991 (5), EAC 16552 (5), EAC 28800 (11). Figueiredo, M.A.: 248 (7), 267 (11), 317 (11), 333 (10), 339 (2), 419 (11). Freitas Filho, F.: UFRN 293 (7). Jardim, J.G.: 5935 (6), 6064 (8), 6142 (7), 6155 (4), 6156 (7), 6176 (6), 6233 (1), 6262 (9). Loiola, M.I.B.: 654 (5), 783 (4), 885 (11), 1005 (7). Martins, M.L.L.: 454 (7). Miranda, A.M.: 5233 (1). Mól, D.F.F.: 47 (8), 48 (7). Oliveira, A.C.P.: 908 (7), 944 (7), 945 (7), 1036 (7). Oliveira, J.: 37 (5). Oliveira, O.F.: 147 (10), 623 (3), 624 (3), 625 (3), 1667 (10). Oliveira, R.C.: 2096 (11). Pereira, R.C.: 3006 (5). Pinheiro, M.P.G.: 11 (7). Projeto Parque das Dunas: 286 (7), 289 (4). Queiroz, E.P.: 2038 (4). Queiroz, R.T.: 540 (6), 541 (6), 592 (8), 609 (11), 617 (6). Ribeiro, A.: 120 (4). Roque, A.A.: 360 (6), 1059 (7), 1244 (7), 1262 (4), 1268 (4), 1270 (8), 1306 (8), 1332 (5), 1425 (7). São-Mateus, W.M.: 04 (8), 46 (7). Sarmento, A.C.: 747 (2). Silveira, E.B.: EAC 46804 (4), EAC 46805 (5). Thomas, W.W.: 15283 (4). Trindade, A.: UFRN 1237 (4). Trindade, M.R.O.: 91 (6). Vasconcelos, S.H.: 40 (5). Vodicka, M.R.: 08 (3). Xavier, L.P.: JPB 2994 (5). 